\title{
Metabolic Studies of Isolated Human Eccrine Sweat Glands
}

\author{
S. Wolfe, G. Cage, M. Epstein, L. Tice, H. Miller, and \\ R. S. GORDON, JR. \\ From the Metabolic Diseases Branch and the Laboratory of Experimental \\ Pathology, National Institute of Arthritis and Metabolic Diseases, Bethesda, \\ Maryland 20014 and the Gerontology Research Center, National Institute \\ of Child Health and Human Development, Baltimore, Maryland 21224
}

\begin{abstract}
A в S T R A C T This paper describes a method for isolating and studying the metabolism of human eccrine sweat glands. (a) Electron microscopy of glands which had been isolated and then incubated for an hour revealed no apparent alteration in morphology. (b) Known variation in gland size (male $>$ female $>$ children) was reflected in the relative rates of lactate production. (c) Lactate production was approximately 1.5 nmoles/ gland per $\mathrm{hr}$ in the absence of glucose and rose to 2.7 at physiological concentrations of glucose (5.6 mmoles/ liter). This amount of lactate production agrees well with the amounts found in sweat. (d) Both adrenergic (epinephrine) and cholinergic (methacholine) stimuli increased lactate production. (e) Glycogen depletion was demonstrated during incubation. $(f) \mathrm{O}_{2}$ consumption was measured and aerobic metabolism was found to account for less than $1 \%$ of the energy derived from anaerobic pathways.
\end{abstract}

These studies demonstrate that the large amounts of lactate appearing in human eccrine sweat can be accounted for by glandular metabolism and that both glycogen and glucose can be used as substrates.

\section{INTRODUCTION}

Studies of the in vitro metabolism of human eccrine sweat glands have heretofore been limited to those of Kosaka (1), who measured $\mathrm{CO}_{2}$ production in skin slices, and those of Schulz et al. (2), who made preliminary observations on the production of lactate by a single surviving sweat gland under nitrogen. We therefore have developed an in vitro system in order to study the energy metabolism and the manner in which

This work was presented in part at the meeting of the American Physiological Society, 21 April 1968, Atlantic City, N. J.

Received for publication 27 April 1970. sweat glands are affected by pharmacologic stimuli. Since lactate is the major organic constituent of sweat, its production was used as an index of the activity of the isolated glands.

\section{METHODS}

Microdissection and incubation. Human eccrine sweat glands were obtained from surgical or biopsy specimens of skin. The specimens were immediately placed in a modified Krebs buffer containing the following: $140 \mathrm{~mm}$ $\mathrm{NaCl} ; 5 \mathrm{~mm} \mathrm{KCl} ; 25 \mathrm{~mm}$ Tris- $\mathrm{HCl}(\mathrm{pH} \mathrm{7.4)}$; bovine serum albumin, $1 \%$; and $1.25 \mathrm{~mm} \mathrm{CaCl}$. All subsequent procedures up to the time of incubation were performed at $4^{\circ} \mathrm{C}$. If the skin specimen was thicker than $2-3 \mathrm{~mm}$, a Stadie-Riggs tissue slicer was used to allow dissection of more glands by exposure of additional surface area. To approximately $10 \mathrm{cc}$ of cold buffer containing the skin specimen, several drops of a $1 \%$ solution of methylene blue were added and, after mixing, the skin was kept in this solution for about $15 \mathrm{~min}$. It was then rinsed in fresh buffer and placed in a small Petri dish which was kept at approximately $4^{\circ} \mathrm{C}$. Using a binocular dissecting microscope and two pairs of stainless steel Dumont No. 5 microforceps, the microdissection was performed. The bluetinged secretory coils of the eccrine sweat glands were easily visible against the white background of collagen fibers. After carefully teasing away the loose collagen immediately surrounding the gland, it was possible to lift the secretory coil out from the adjacent tissue by picking up some of the few collagen fibers still adhering. Using this technique, the secretory coil was separated from the straight part of the sweat duct. After transfer to a second Petri dish of fresh buffer, remaining collagen fibers and fat cells were removed It was possible to dissect as many as 30 glands per hr. From 5 to 10 glands were then transferred to each of several small test tubes containing $0.6 \mathrm{ml}$ of the above buffer. At $0,30,60$, and $120 \mathrm{~min}$ of the incubation at $37^{\circ} \mathrm{C}, 0.1 \mathrm{ml}$ samples were removed and frozen for lactate determination. Although treatment with methylene blue facilitated dissection of the glands, it was possible to remove them without supravital staining. In several experiments, simultaneous determinations of lactate production from stained and unstained preparations revealed no differences. 
TABLE 1

Effect of Age and Sex on Lactate Production by Human Eccrine Sweat Glands

\begin{tabular}{cc}
\hline Age & $\begin{array}{c}\text { Lactate } \\
\text { production }\end{array}$ \\
\hline$y r$ & nmoles $/$ gland \\
per hr in 0.005 \\
M glucose
\end{tabular}

Children

\begin{tabular}{|c|}
\hline 10 \\
\hline 9 \\
\hline \\
\hline
\end{tabular}

Females

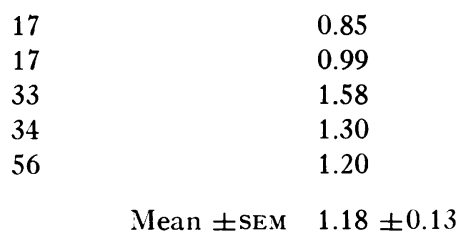

Males

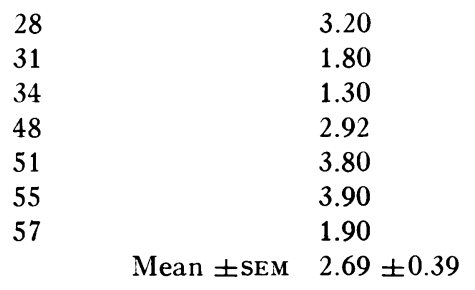

Lactate. Lactate was determined by an enzymatic method, measuring spectrophotometrically the conversion of NAD to $\mathrm{NADH}$ in the presence of lactate dehydrogenase (3).

Glycogen. The glycogen content was determined by removal of glucose and glucose esters using methanol, and acid hydrolysis of whole glands to convert glycogen to glucose (4). Glucose was then determined by a glucose oxidase technique (5).

\section{RESULTS}

Effect of age and sex on lactate production. It has been previously noted that the size of human eccrine sweat glands increases with general body growth and that males have larger sweat glands than females (6). These differences in size were quite apparent during the dissection and are reflected in the relative rates of lactate production from children (younger than $15 \mathrm{yr}$ ), females, and males, as shown in Table I.

Effect of glucose on lactate production. Fig. 1 shows the rates of lactate production in adult male glands incubated in the absence of glucose, with $0.1 \%$ glucose $(0.0056$ mole/liter $)$, or with $1 \%$ glucose $(0.056$ mole/liter). In the presence of $0.0056 \mathrm{~m}$ glucose, lactate production increased from control levels of $1.53 \pm 0.14$ nmoles/gland per $\mathrm{hr}$ to $2.72 \pm 0.43$ (mean \pm SEM).

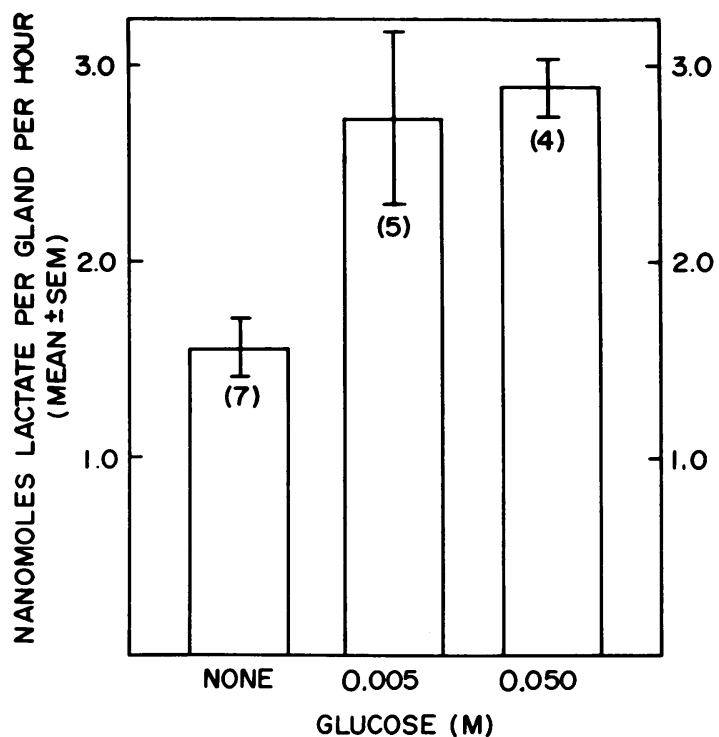

FIGURE 1 Effect of glucose on lactate production by human eccrine sweat glands. Glands were isolated and incubated for one hour (see Methods). Numbers in parentheses refer to the number of experiments performed.

Response to pharmacologic stimuli. Methacholine or epinephrine, each at a concentration of 0.001 mmole/ liter, was added in several experiments to see if either had a stimulatory effect on lactate production (Table II). The stimulatory effect of mecholyl could be abolished with $0.01 \mathrm{~mm}$ atropine but the stimulatory effect of epinephrine was unaffected.

Glycogen content. Analysis of glands from nine male adults, before incubation, showed the glycogen content to be $0.98 \pm 0.12$ nmoles/gland (mean \pm SEM) (ex-

TABLE II

Effect of Methacholine and Epinephrine on Lactate Production by Human Eccrine Sweat Glands

\begin{tabular}{ccccccc}
\hline $\begin{array}{c}\text { Exp. } \\
\text { No. }\end{array}$ & Age/Sex & Glucose & Control & $\begin{array}{c}\text { Metha- } \\
\text { choline }\end{array}$ & $\begin{array}{c}\text { Stimu- } \\
\text { lation }\end{array}$ \\
\hline & $y r$ & & & \multicolumn{3}{c}{ nmoles lactate/ } \\
gland per $h r$ & $\%$ \\
1 & 12 & F & 0 & 0.46 & 1.02 & +122 \\
2 & 42 & M & 0 & 1.00 & 1.75 & +75 \\
3 & 48 & M & 0 & 1.54 & 2.92 & +90 \\
4 & 10 & F & $0.005 \mathrm{M}$ & 0.22 & 0.37 & +68 \\
5 & 17 & F & $0.005 \mathrm{M}$ & 0.99 & 1.38 & +39 \\
6 & 31 & M & $0.005 \mathrm{M}$ & 1.80 & 1.97 & +9 \\
7 & 28 & M & $0.005 \mathrm{M}$ & 3.20 & 2.98 & -7 \\
& & & & & Epinephrine & \\
1 & 33 & F & $0.005 \mathrm{M}$ & 1.58 & 2.98 & +89 \\
2 & 56 & F & $0.005 \mathrm{M}$ & 1.20 & 2.95 & +146 \\
3 & 57 & M & $0.005 \mathrm{M}$ & 1.90 & 2.50 & +32 \\
4 & 51 & M & $0.005 \mathrm{M}$ & 3.80 & 3.90 & +3 \\
\hline
\end{tabular}

Glands were incubated for $1 \mathrm{hr}$. Methacholine or epinephrine was added to a final concentration of $0.001 \mathrm{mmole} / \mathrm{liter}$. 


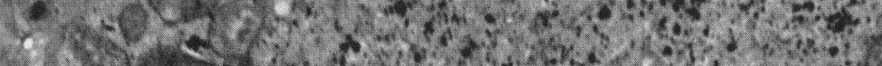
ina its?




TABLE III

Glycogen Depletion in Human Eccrine Sweat Glands

\begin{tabular}{cccc}
\hline & \multicolumn{3}{c}{ Glycogen (as glucose) } \\
\cline { 2 - 4 } Exp. & Initial & Final & Decrease \\
\hline & \multicolumn{4}{c}{ nmoles/ } \\
gland & \\
1 & 0.82 & 0.32 & 0.50 \\
2 & 0.89 & 0.28 & 0.61 \\
\hline
\end{tabular}

pressed in terms of nanomoles of glucose per gland) or the equivalent of about 2 nmoles of lactate per gland. Table III shows the results of experiments in which glycogen content was measured both before and after incubation in buffer which contained no glucose.

Oxygen consumption-cartesian diver technique. A modified ampulla diver technique (7) was employed to determine the $\mathrm{O}_{2}$ uptake of isolated sweat glands. Three individual glands from an adult male skin biopsy were each introduced with approximately $1 \mu$ liter of Krebs' Tris buffer without glucose or albumin into one end of a Pyrex capillary (o.D. $0.025 \pm 0.001$ in., I.D. 0.022 \pm 0.001 in.) which had been previously drawn out to an I.D. of $30 \mu$ at its opposite end. The large diameter opening was then sealed and the air phase volume was adjusted in a $0.1 \mathrm{~N} \mathrm{NaOH}$ balancing chamber. Temperature was maintained at $37.0 \pm 0.001{ }^{\circ} \mathrm{C}$ using a Bayley Precision Temperature Controller. The diver was equilibrated for $15 \mathrm{~min}$ after which readings were taken every $30 \mathrm{~min}$ for $5 \mathrm{hr}$. The sensitivity of the method is 0.02 nliter $\mathrm{O}_{2} / \mathrm{hr}$. The results are summarized in Table IV.

Assuming 6 moles of $\mathrm{O}_{2}$ are needed to oxidize 1 mole of glucose to $\mathrm{CO}_{2}$ via the tricarboxylic acid cycle and using 0.54 nliters $\mathrm{O}_{2} / \mathrm{hr}$ as the average $\mathrm{O}_{2}$ uptake for each of the three glands, the measured $\mathrm{O}_{2}$ consumption would account for the oxidation of only 0.0036 nmoles of glucose per hr.

Electron microscopy studies. Following many, but not all incubations, glands were fixed in glutaraldehyde and prepared for electron microscopy. As can be seen in Fig. 2, the ultrastructure is quite intact, indicating that neither the dissection nor subsequent incubation had significantly damaged the gland.

\section{DISCUSSION}

These studies demonstrate that it is possible to isolate human eccrine sweat glands and perform in vitro studies of their metabolism. The glands appear not only
TABLE IV

Oxygen Consumption by Human Eccrine Sweat Glands

\begin{tabular}{ccc}
\hline $\begin{array}{c}\text { Sample } \\
\text { No. }\end{array}$ & Diameter & O$_{2}$ uptake \\
\hline & $\mu$ & $n l / h r$ \\
1 & $700 \pm 25$ & $0.32 \pm 0.032$ \\
2 & $600 \pm 25$ & $0.71 \pm 0.071$ \\
3 & $625 \pm 25$ & $0.60 \pm 0.060$ \\
\hline
\end{tabular}

to maintain their morphologic integrity but are also capable of responding to pharmacologic stimuli known to stimulate sweating in vivo when injected intradermally.

The lactate production as measured in these studies compares very closely with the amounts of lactate produced during thermal sweating. If the number of glands in a normal man is approximately 3 million (6) and each gland produces about 3 nmoles of lactate per hr, this would amount to 9 mmoles of lactate per hr. Adult males can readily produce 1 liter of sweat per $h^{-1}$ and the average lactate concentration in sweat is 8-12 mmoles/liter. The present studies therefore provide a direct demonstration that the large amounts of lactate present in human eccrine sweat can be accounted for by glandular metabolism.

Histological evidence for glycogen depletion in eccrine sweat glands during sweating was first demonstrated by Yayama (8). The present studies show glycogen content to be equivalent to 2 nmoles of lactate per gland and show that, in the absence of glucose, an average of 1.53 nmoles of lactate is produced in the $1 \mathrm{st} \mathrm{hr}$. Thus, by the end of $1 \mathrm{hr}$ of incubation, lactate production sufficient to account for the utilization of most glandular glycogen has occurred. In the presence of glucose, the amount of lactate produced in $2 \mathrm{hr}$ of incubation is much greater than can be accounted for by glycogen depletion.

Recent studies ${ }^{1}$ show that with adequate hydration, acclimatized adult males can produce more than 3 liters of sweat per $\mathrm{hr}$, containing $8-10 \mathrm{mEq} /$ liter of lactate. This amount of lactate is also far in excess of that which could be accounted for by glycogen depletion alone; moreover, it has been demonstrated that in acclimatized males there is no histological evidence for glycogen depletion during sweating (9). In vivo studies there-

${ }^{1}$ Cage, G., S. Wolfe, R. H. Thompson, and R. S. Gordon, Jr. Effects of water intake on thermal sweating in normal human volunteers. J. Appl. Physiol. In press.

FIGURE 2 Human eccrine sweat gland. After incubation for $1 \mathrm{hr}$, the gland was fixed and prepared for electron microscopy. This is a cross section through the secretory portion showing both dark and light cells. $\times 7800$. 
fore suggest that glucose must also be utilized as a substrate for the metabolism of eccrine sweat glands. The present studies demonstrate the dependence of lactate production on glucose concentration and are thus in accordance with the utilization of both glycogen and glucose during sweating.

Although sweat glands contain numerous mitochondria and are abundantly supplied with well oxygenated blood during thermal sweating, this tissue appears to metabolize glucose and glycogen primarily anaerobically as evidenced by the large amount of lactate produced both in vivo and in vitro. Indeed, Weiner and van Heyningen (10) calculated that anaerobic metabolism of either glycogen or glucose to lactate would be sufficient to account for the energy of formation of even the most dilute sweat. The studies of oxygen consumption show that for the $1.5 \mathrm{nmoles} / \mathrm{hr}$ of lactate produced less than 0.004 nmoles (or less than $1 \%$ ) are metabolized aerobically. ${ }^{2}$

\footnotetext{
${ }^{2}$ Due to the problem of oxidation of substrate by means other than glandular metabolism (such as bacterial metabolism), glucose was omitted from the medium during the studies on oxygen consumption It is therefore possible that in the presence of glucose there might be more than $1 \%$ aerobic metabolism; but even with such a possible change, the metabolism would still be largely anaerobic, as suggested by the glucose-dependent increases in lactate metabolism in vitro.
}

\section{REFERENCES}

1. Kosaka, S. 1953. Studies on the glycolysis of human skin with reference to that of sweat glands. Jap. J. Physiol. 3: 127.

2. Schulz, I., K. J. Ullrich, E. Fromter, H. M. Emrich, A. Frick, U. Hegel, and H. Holzgrove. 1965. Micropuncture experiments on human sweat gland. In $\mathrm{Re}-$ search on Pathogenesis of Cystic Fibrosis. P. A. diSant'Agnese, editor. Wickersham Printing Co., Lancaster, Pa. 136.

3. Hohorst, H-J. 1963. L-(+)-lactate. Determination with lactic dehydrogenase and DPN. In Methods of Enzymatic Analysis. H. U. Bergmeyer, editor. Academic Press Inc., New York. 266.

4. Greenberg, L. J., and D. Glick. 1962. Micro method for glycogen determination. Biochemistry. 1: 452.

5. Washko, M. E., and E. W. Rice. 1961. Determination of glucose by an improved enzymatic procedure. Clin. Chem. 7: 542 .

6. Kuno, Y. 1956. Human Perspiration. Charles C Thomas, Springfield, Ill.

7. Zeuthen, E. 1953. Growth as related to the cell cycle in single cell cultures of Tetrahymena piriformis. J. Embryol. Exp. Morphol. 1: 239.

8. Yuyama, H. 1935. On the histological examination of distribution of glycogen in the skin of leprosy with special reference to the relationship between the function of sweat glands and the changes of glycogen content. Jap. J. Dermatol. Urol. 37: 811.

9. Dobson, R. L. 1960. The effect of repeated episodes of profuse sweating on the human eccrine sweat glands. J. Invest. Dermatol. 35: 195.

10. Weiner, J. S., and R. E. van Heyningen. 1952. Lactate content of sweat. J. Appl. Physiol. 4: 734. 